The Open Construction and Building
Technology Journal
CrossMark
Content list available at: www.benthamopen.com/TOBCTJ/
DOI: $10.2174 / 1874836801610010220$

\title{
Discrete Element Analysis of the Shear Resistance of Planar Walls with Different Bond Patterns
}

\author{
Ferenc Szakály, Zsolt Hortobágyi and Katalin Bagi \\ Department of Structural Mechanics, Budapest University of Technology and Economics, Budapest, Müegyetem, \\ Hungary
}

\begin{abstract}
The paper presents discrete element simulations of the in-plane horizontal shear of planar walls having different bond patterns. The aim of the analysis was to decide whether the shear resistance could be improved by applying patterns containing vertical bricks. The results show that the presence of vertical bricks increases the shear resistance in case of low vertical confining load only, and the length-to-height ratio of the wall also significantly affects the shear resistance.
\end{abstract}

Keywords: Brick bonding, 3DEC, Distinct element, Failure, In-plane shear, Load bearing, Masonry, Softening.

\section{INTRODUCTION}

Planar walls are the most widely applied components of masonry and infilled reinforcement frame buildings. They are known for being vulnerable for in-plane horizontal shear, which significantly affects the load bearing capacity of the whole structure. This feature is the main reason of many damages of masonry buildings exposed to earthquakes and other soil motions. The magnitude of the vertical load acting on shear walls significantly affects both the failure mechanism and the load bearing capacity. Depending on the structural role of the wall, this magnitude can vary on a large scale. In case of infilled frames where the mechanical effect of the masonry is usually ignored in the practical design, the vertical load transferred to the masonry is extremely low (below $1 \mathrm{kN} / \mathrm{m}$ ), while in case of multistory masonry buildings it may take high values (e.g. $100 \mathrm{kN} / \mathrm{m})$. As an example, the crack pattern of a masonry infill loaded by horizontal shear until failure can be seen in Fig. (1.1).

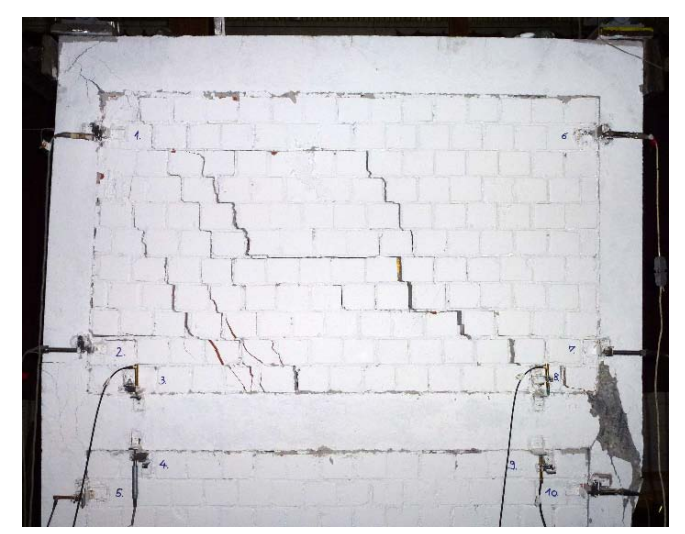

Fig. (1.1). Crack pattern of a sheared planar wall in reinforced concrete frame (photo: second author).

\footnotetext{
* Address correspondence to this author at the Department of Structural Mechanics, Budapest University of Technology and Economics, Budapest, Múegyetem, Hungary; E-mail: szakalyf@eik.bme.hu.
} 
Due to their complex material and structural behaviour, modelling of masonry structures has always been a significant challenge for structural engineers. Nowadays the most popular numerical approaches are the methods based on Limit State Analysis (e.g. O’Dwyer, 1999; Block and - Ochsendorf, 2007; Baggio and Trovalusci, 2000 [1 - 3]), the different finite element techniques (FEM), and the several versions of the discrete element method (DEM) (see Section 2.1). Roca et al. (2010) and Baraldi et al. (2015) [4, 5] gave a deep and detailed overview about these possibilities. Giamundo et al. (2014) [6] compared the different modelling strategies for the special case of low strength masonry structures. Equivalent continua like Cosserat models, can also be applied in FEM. In Trovalusci and Masiani (2003) [7] derived a nonlinear Cosserat model was derived and applied successfully for planar walls. Casolo (2006) [8] introduced an orthotropic Cosserat model based on the homogenization of the properties of bricks and mortar in a planar wall. With the help of the virtual work principle, Trovalusci et al. (2014) [9] derived a micropolar, a second gradient and a classical continuum model on the basis of rigid particle lattice systems. Identification of material parameters is also a complex task. The conventional and popular way to obtain them is to perform direct small-scale laboratory tests on the different constituents of the masonry, and then derive the phenomenological characteristics through a proper homogenization. However, it is not the only way to determine them.Sarhosis et al. (2014) [10] applied a more precise and complex method, transforming the task into an optimization problem. With the help of laboratory experiment a characteristic response of the structure was measured first (e.g. ultimate load, load at first visual crack etc.), then with successive numerical simulations the material parameters were identified by minimizing the deviation of the response between the numerical and experimental results.

In the present study DEM is applied for performing virtual (i.e. computer-simulated) experiments instead of direct laboratory measurements. The material parameters of the DEM models are taken from the laboratory experiments of Fódi (2011) [11]. The aim of the virtual experiments is the following.

When the bricks or voussoirs are relatively strong and the mortar is weak or missing, there are three main characteristic failure modes of sheared planar walls, depending on their length to height ratio $(l / h)$ and the material properties: (i) horizontal shear plane developing; (ii) diagonal cracking; (iii) rocking around the crushing corner. These modes are illustrated in Fig. (1.2) where the gaps indicate the cracking pattern.

The final damage pattern and ultimate shear load are affected by factors such as material properties, ratio of the main dimensions and the applied bond pattern. The most widespread brick pattern is the English bond (first picture in Fig. (1.2)). However, vertically installed bricks may improve the shear performance. Thus the aim of the present study is to see whether suitably chosen bond patterns can increase the load bearing capacity of planar walls. Four different bond patterns are investigated, analyzing the effect of the vertical load magnitude and of the length/height ratio. (The bricks are assumed to be strong so that the failure is due to contact cracking or sliding in all cases considered in the present paper).
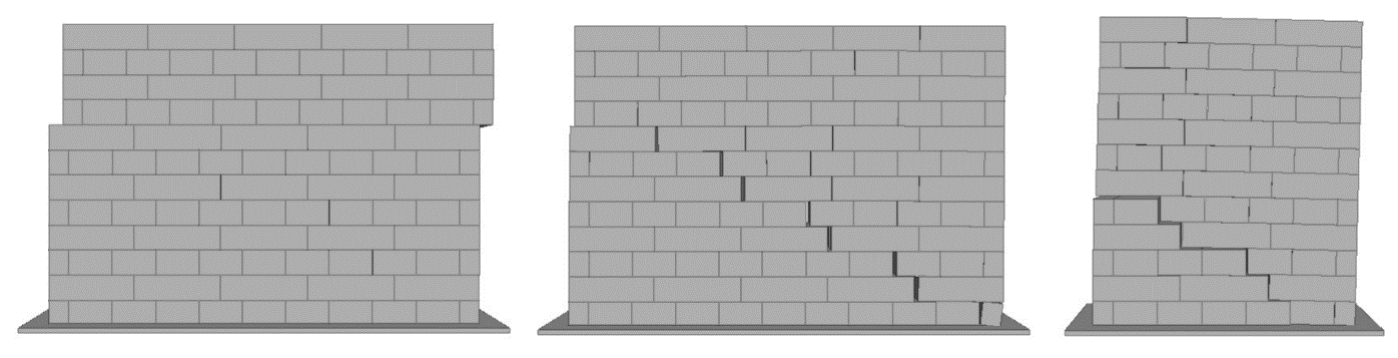

Fig. (1.2). Characteristic failure modes of planar masonry walls (from left to right: shear plane, diagonal cracking and rocking) (3DEC simulations).

\section{TOOL OF THE SIMULATIONS: DEM AND THE APPLIED SOFTWARE}

\subsection{The Discrete Element Method}

The discrete element method (DEM) is a powerful tool for the modelling of masonry structures where contact separation and frictional sliding between the bricks or stones are common. DEM was first introduced for the simulation of fractured rocks by P.A. Cundall (1971) [12], and has been applied in the engineering practice approximately since the 1990s, when computer hardware became powerful enough to simulate realistic problems on average PCs. A discrete element model considers the structure to be a collection of separate blocks, "discrete elements", each of which is able to move and - in most software - to deform independently of each other. The blocks may come into contact with each 
other hence distributed forces can be transmitted from one block to another, causing stresses and deformations in the blocks. According to the criteria formulated by Cundall and Hart (1992) [13], a numerical technique is a discrete element model if

(1) the elements are able for finite (i.e. large) translations and rotations; and

(2) complete detachment as well as formulation of new contacts are allowed and automatically followed.

The second criterion means two important differences from the finite element method (FEM): there are no continuity conditions at the common points of the contacting elements, and the elements are continuously checked throughout the calculations whether they get into contact with each other.

The large displacements are usually followed with the help of some kind of a time-stepping scheme: most DEM codes determine the characteristic motions of the analysed system (leading from an initial geometry to the equilibrium position corresponding to the loads) along a series of small but finite time intervals, applying Newton's laws of motion. Using DEM, a simulated structure may split into pieces (e.g. a stair may fall into individual treads) which may even bounce into each other on the ground forming a heap balanced under its own weight. There are innumerable different versions of discrete element techniques - the elements may be rigid or deformable, spherical, polyhedral or irregular, the time integration may be explicit or implicit, or may be replaced by a quasi-static method, etc. A very useful introduction is given by O'Sullivan (2011) [14] on the most important techniques ${ }^{1}$. An excellent overview is given by Lemos (2007) [15] on the different mathematical and practical approaches to simulate masonry structures with the help of DEM, including practical engineering applications as well.

Despite the few doubts regarding its usage (Huerta, 2008) [16], the capability to simulate partial or complete separation of blocks from each other and contact sliding between the voussoirs makes DEM a suitable choice. Therefore, a carefully calibrated DEM model is a powerful tool for the analysis of masonry structures. Such a DEM model was applied by Sarhosis et al. (2014) [17] for the analysis of masonry infilled frames with openings. Because of its ability to follow frictional sliding, failure processes and collapse histories in detail, DEM was chosen in the present study to serve as the basic tool of the investigations introduced in the present paper.

\subsection{The Applied Software}

The commercial DEM code named 3DEC was applied in the calculations. UDEC ("Universal Distinct Element Code"), the 2D ancestor of 3DEC, was originally developed for the modelling of fractured rocks P.A. Cundall (1971) [12], but today its $2 \mathrm{D}$ and $3 \mathrm{D}$ versions are widely used in the engineering practice also for masonry structures.

The discrete elements in 3DEC may have any polyhedral shape, and they can be made deformable in such a way that they are divided into simplexes (tetrahedra in 3D) which serve as uniform-strain finite elements. The nodes of the simplexes ("gridpoints") of the deformable elements are the basic units of the analysis. The mass of a gridpoint is defined with the help of the volume of the Voronoi cell around that gridpoint within the element, and different forces ${ }^{2}$ may act on this volume assigned to the gridpoint. The basic step of the calculations is to determine the displacements of these nodes during a small finite $\Delta t$ time interval, and this is done by Newton's second law of motion (forceacceleration law). An explicit time integration scheme, based on central differences, is used for simulating the mechanical behaviour (motions, from them strain increments, changes of stresses and forces, etc.) over time: the simulation of the state changing under a given loading process is achieved by step-by-step calculation of the incremental motions of the reference points or gridpoints.

The joints between the elements may have, in principle, two different roles depending on the intention of the modeller. The first option (the one that was used in this present study) is that the joints represent some kind of mortar layer (or e.g. clay layer in fractured rocks) having a finite thickness in reality. In this case, the material parameters of the joints express the deformability of these layers and their failure criteria. Therefore a normal and a tangential stiffness (i.e., resistance to relative translation) have to be prescribed along with either some fracture criteria (normal and shear strength) and perhaps a friction coefficient in order to define the conditions when the joints fail.

\footnotetext{
${ }^{1}$ A special value of that book is that the issue of numerical stability, which is particularly important in the stability analysis of masonry vaults and domes, is discussed in detail.

${ }^{2}$ e.g. weight, distributed forces expressed by neighbouring Voronoi cells because of the stresses inside the simplexes, contact forces transmitted from contacting elements.
} 
The other option is most suitable if there is no material layer between the blocks in the real system. In this case the aim is to simulate dry contacts, or perhaps to neglect the weak mortar in an old masonry structure. The friction coefficient of the joints still has a real physical meaning, expressing the sliding criterion of the two contacting bricks or stone blocks along each other. The contact stiffnesses, on the other hand, are artificial numerical penalty parameters only. This option was not applied in the present paper.

\subsection{Geometry and Material Properties of the Simulated Walls}

During the simulations four different bond brick patterns were investigated, each made of conventional Hungarian solid masonry units (120x250x65 mm³, see Porotherm, 2014 [18]). However, in the models simplified type of micro modelling was applied, which means that only the masonry units had a finite volume, while the originally $\sim 1 \mathrm{~cm}$ mortar layers were included in the size of the bricks and they were represented by zero-thickness contact surfaces between the blocks.

Fig. (2.1) shows the four different bond patterns analysed in the simulations. The classical English bond and the herringbone pattern are well-known in the engineering practice; an X-pattern and a V-pattern (both containing vertical bricks arranged in a special way) were invented to try whether they have advantages to the traditional patterns.
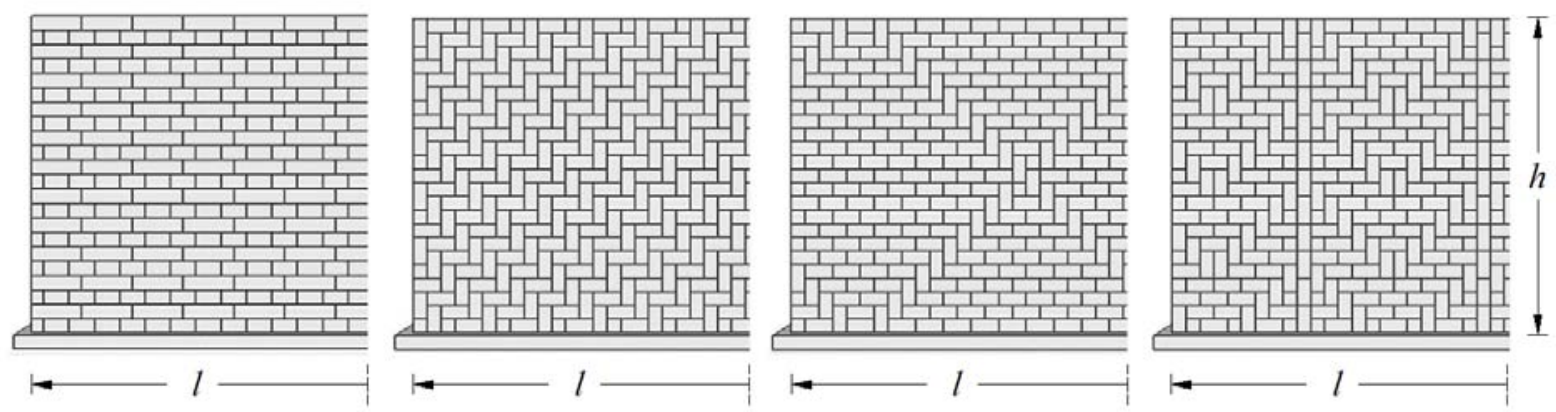

Fig. (2.1). The investigated bond patterns from left to right: English bond, diagonal herringbone pattern, X-pattern, and V-pattern.

The total dimensions of the walls having different patterns were very close to each other (about 231(233) - 462(467) $\mathrm{cm} \times 161 \mathrm{~cm} \times 25 \mathrm{~cm}$, the small differences came from the different numbers of truncated bricks applied to the different bond patterns). Walls having different length-to-height ratios (Table 2.1) were prepared for each bond pattern, in order to analyse the effect of the wall shape.

Table 2.1. The applied $l / h$ ratios.

\begin{tabular}{|l|c|c|c|c|}
\hline & $\# 1$ & $\# 2$ & $\# 3$ & $\# 4$ \\
\hline Length/height $(l / h)$ ratios [-] & 1.42 & 1.89 & 2.36 & 2.84 \\
\hline
\end{tabular}

In all cases the masonry units had linearly elastic, isotropic mechanical behaviour while the joints (mortar layers) followed the cohesionless Coulomb friction law. Table $\mathbf{2 . 2}$ shows the parameters of the different models: the density $\rho$, bulk and shear modulus $K$ and $G$ corresponding to the bricks, the normal stiffness $k_{n}$, shear stiffness $k_{s}$ and internal friction angle $\varphi$ corresponding to the joints. The applied material parameters are based on the experimental results in Fódi (2011) [11].

Table 2.2. The applied material parameters.

\begin{tabular}{|l|c|c|c|}
\hline & $\rho\left[\mathrm{kg} / \mathrm{m}^{3}\right]$ & $K\left[\mathrm{~N} / \mathrm{m}^{2}\right]$ & $G\left[\mathrm{~N} / \mathrm{m}^{2}\right]$ \\
\hline Brick model & 1428 & $1.1 \mathrm{e} 10$ & $8.33 \mathrm{e} 9$ \\
\hline & $k_{n}\left[\mathrm{~N} / \mathrm{m}^{2} / \mathrm{m}\right]$ & $k_{s}\left[\mathrm{~N} / \mathrm{m}^{2} / \mathrm{m}\right]$ & $\varphi\left[{ }^{\circ}\right]$ \\
\hline Joint model & $1 \mathrm{e} 10$ & $7 \mathrm{e} 9$ & 38 \\
\hline
\end{tabular}

\subsection{Loads and Boundary Conditions}

The wall models were supported with a foundation block below (see Fig. (2.2)): the nodes of this lowest block were fixed against any translations. The applied loads consisted of three components (see Fig. (2.2) again): (i) first the selfweight of the blocks was applied; (ii) then a vertical stabilizing load was put on the top of the wall; (iii) finally, as 
the main loading component of the analysis, a monotonically increasing horizontal lateral load was applied with the help of a simulated hydraulic jack.

The magnitude of the stabilizing vertical load was one of the parameters whose effect on the shear resistance (i.e. on the magnitude of the ultimate shear load and on the failure mechanism) was investigated. Six different values were used and the corresponding shear resistances were determined for each (see the applied magnitudes in Table (2.3)).

Table 2.3. The different vertical load magnitudes.

\begin{tabular}{|l|c|c|c|c|c|c|}
\hline & $\# 1$ & $\# 2$ & $\# 3$ & $\# 4$ & $\# 5$ & $\# 6$ \\
\hline Vertical load magnitudes $[\mathrm{kN} / \mathrm{m}]$ & 0.87 & 4.35 & 8.7 & 21.74 & 43.48 & 86.96 \\
\hline
\end{tabular}

The total loading process consisted of the following steps. First of all, the foundation element at the bottom of the wall was supported against all translational velocities while all of the bricks were free to move and deform, and the gravitational load of the bricks was applied. After finding the equilibrium under selfweight, the vertical load was put on the top surface of the wall as a uniformly distributed load (Fig. 2.2). In order to ensure quasi-static loading circumstances, every vertical load was applied in about thirty steps with a careful balancing process after each.

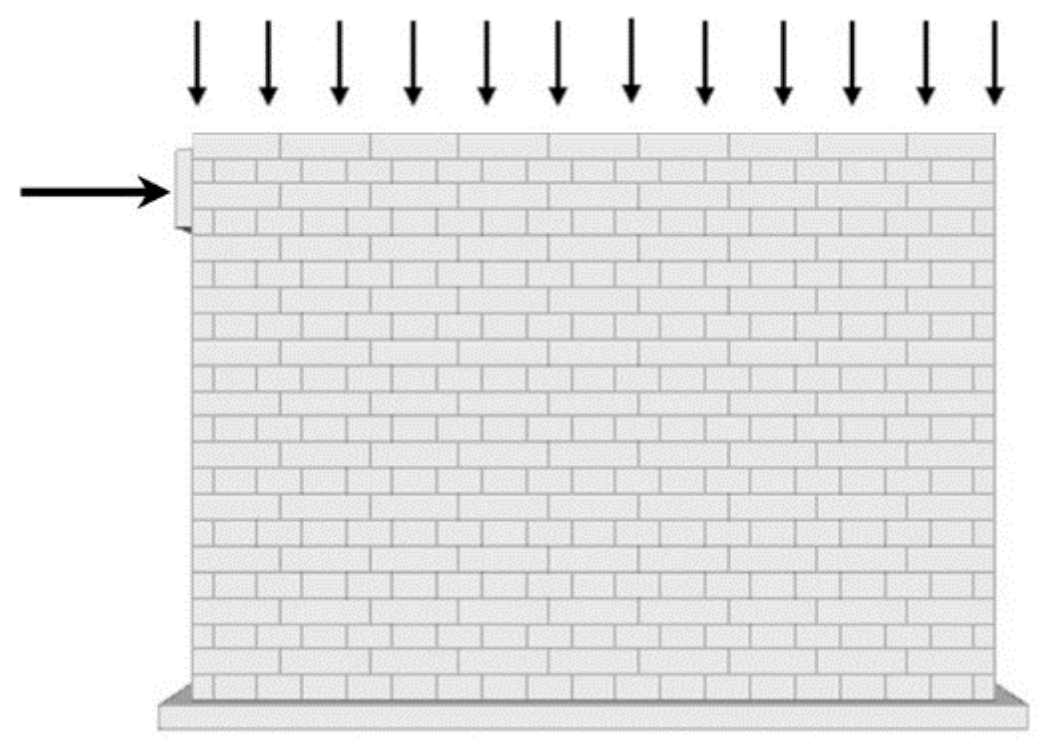

Fig. (2.2). The applied vertical load and the horizontal shear force expressed by a lateral brick.

The horizontal shear loading was expressed with the help of a horizontally moving velocity-controlled lateral block, simulating the hydraulic jack usually applied in laboratory experiments. In order to avoid the sudden impact of the block into the edge of the wall and to preserve the quasi static characteristic of the process, the procedure consisted of consecutive loading and equilibrating phases. In a loading phase the magnitude of the prescribed velocities of the side block was defined according to a special function (see Fig. (2.3)), and altogether $1 \mathrm{~mm}$ translation was accumulated. Then an equilibrating phase followed: the velocities were set to zero, and the model was equilibrated (cycling was continued until the average unbalanced nodal force resultant divided by the average load acting on the nodes becomes smaller than $10^{-5}$ ) In the loading phase the velocity of the loading block first gradually increases from 0.005 to 0.015 $\mathrm{m} / \mathrm{s}$ (first third of the total loading phase), then the velocity is kept constant in the middle stage (second third of the loading phase), and finally it decreases back to $0.005 \mathrm{~m} / \mathrm{s}$ in the same way (last third of the loading phase). The discrete values of this function were calculated in such a way that a total $1 \mathrm{~mm}$ translation was produced until the velocity decreased to zero (see Fig. (2.3)). Note that the area under the red line is $1 \mathrm{~mm}$ altogether. 


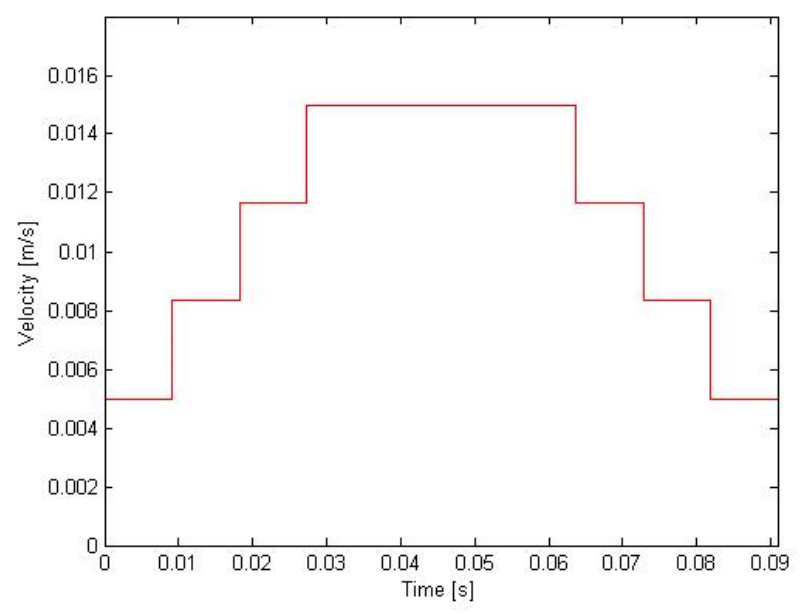

Fig. (2.3). The prescribed function for the definition of the translational load.

The aim of the simulations is to determine the ultimate load for different bond patterns and vertical load magnitudes. Since the definition of 'load bearing capacity' is not unambiguous for masonry structures, its concept has to be uniquely defined before a numerical analysis. In this study, the load bearing capacity is defined as the first local maximum on the force-displacement diagrams, which is often (but not always) also the highest occurring value. For the better understanding of the definition, the following table.

Fig. (2.4) shows three different load-displacement scenarios, and the ultimate shear load is marked with a red circle in every case.

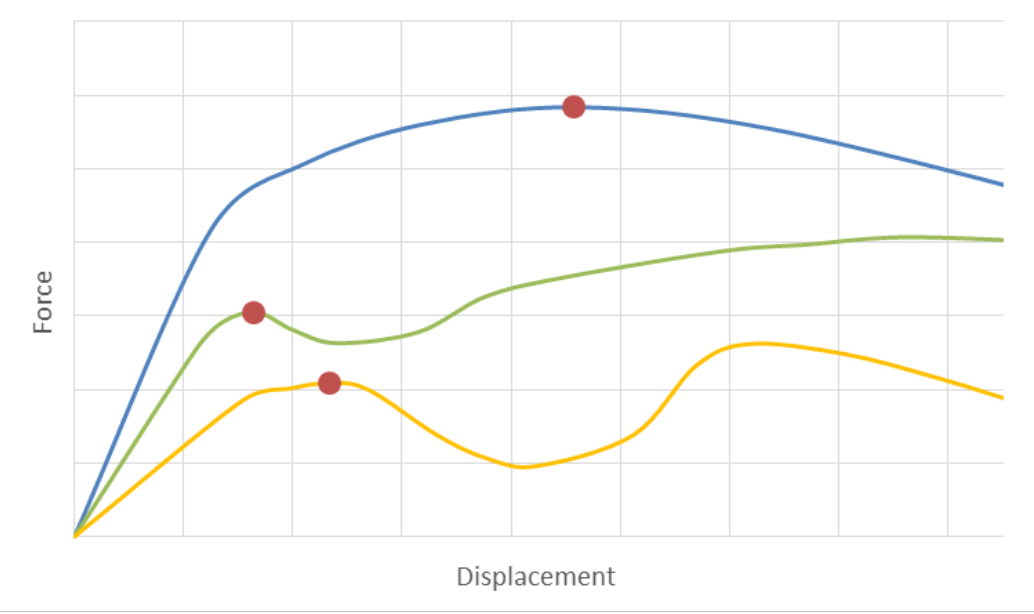

Fig. (2.4). Definition of ultimate load for different load-displacement scenarios.

\subsection{Convergence Analysis}

In the 3DEC model each deformable block (or brick) is subdivided into uniform-strain finite elements. Following the FEM protocols, a convergence analysis is required to eliminate the error originated from a perhaps too rare mesh. For this purpose, the same problems were repeated in 3DEC with different mesh sizes, namely the English and Xpattern walls with slightly smaller dimensions (in order to reduce the necessary computational time) under $86.96 \mathrm{kN} / \mathrm{m}$ vertical load. Since the ultimate shear load will be used as the main characteristic determined in the simulations, the load bearing capacity of these walls is chosen to be the basis of the convergence analysis too. The density of the mesh is characterized with the help of three numbers which how many finite elements are applied along the specific edges (for example $1 \times 2 \times 3$ means that the block is divided into one part along the shortest, two parts along the middle and three 
parts along the longest edge). The results of the analysis can be seen in Fig. (2.5).

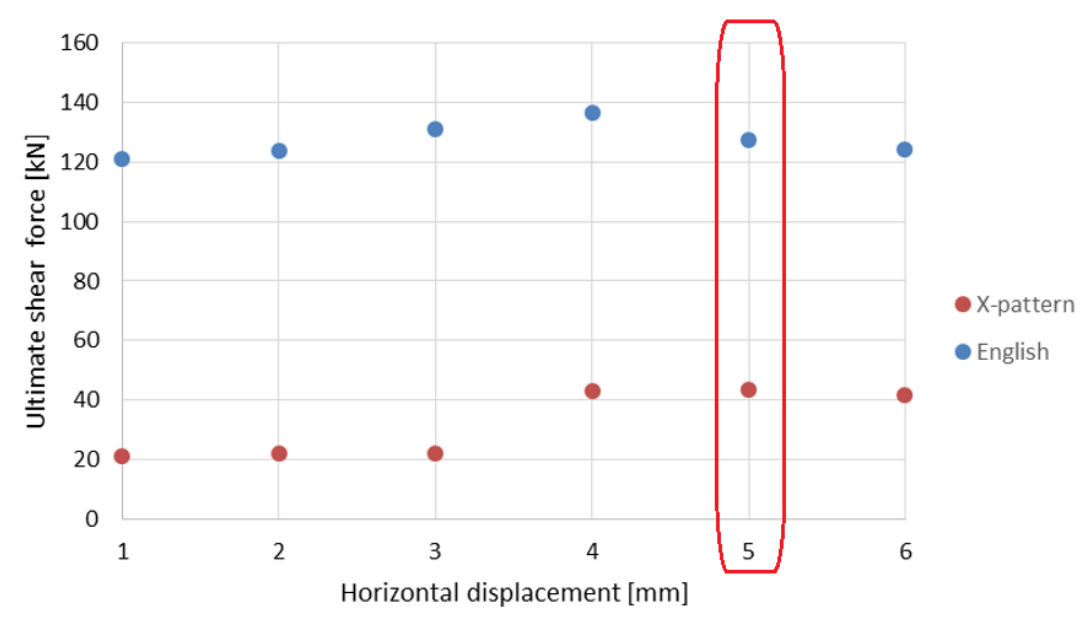

Fig. (2.5). The result of the convergence analysis.

According to the Fig., six different mesh sizes are investigated, namely from 1 to 6 on the diagram (using the previously introduced notation): $1 \times 2 \times 2,2 \times 2 \times 2,2 \times 2 \times 3,2 \times 3 \times 3,2 \times 3 \times 4$, and $3 \times 3 \times 4$. The results show that the fifth one $(2 \times 3 \times 4)$ is already enough to be used during the simulations because the difference between the fifth and sixth cases is negligible. The applied subdivision is shown in Fig. (2.6).

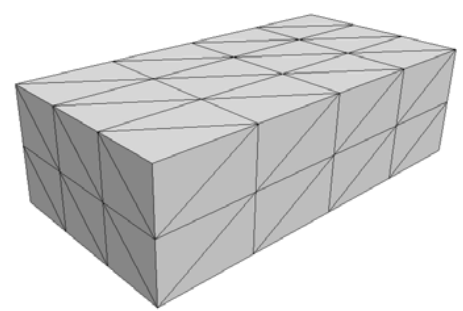

Fig. (2.6). The applied finite element mesh of a brick element.

The small loading block on the left of the wall simulating the hydraulic jack is also subdivided into $2 \times 3 \times 4$ elements. However, since all its FEM nodes are translated with exactly the same prescribed displacement, the loading block does not deform, and the details of its subdivision are indifferent.

The mesh generator of the 3DEC software is based on a random algorithm, consequently if the same problem is intended to be repeated (with same mesh density), different results may be received due to the slightly different random finite element meshes inside the discrete elements. In case of rare meshes it can lead to a serious difference between the results, thus in contrast with the FEM programs, the scatter of the results depending on the mesh density has also to be checked. The shearing process of the English wall with $21.74 \mathrm{kN} / \mathrm{m}$ vertical load was performed twice with tetrahedral subdivision, and the corresponding force-displacement diagrams were compared. The diagrams belonging to the two different meshes practically perfectly coincided, so the subdivision of each brick into $2 \times 3 \times 4$ finite elements was proven to be dense enough.

\section{RESULTS OF THE SIMULATIONS}

\subsection{Shear Behaviour Depending on the Vertical Load}

This section introduces the dependence of the shear behaviour on the magnitude of the constant vertical load acting on the top of the walls. All models considered in this section were around $2.31-2.33 \mathrm{~m}$ long according to the number of truncated bricks in the different patterns. The $l / h$ ratio was approximately equal to 1.42 . The herringbone pattern is not symmetric. Therefore, in addition to shearing from left, the process was also performed from the opposite direction, 
having the hydraulic jack on the right side (this will be denoted as "Herringbone_R" in the diagrams below).

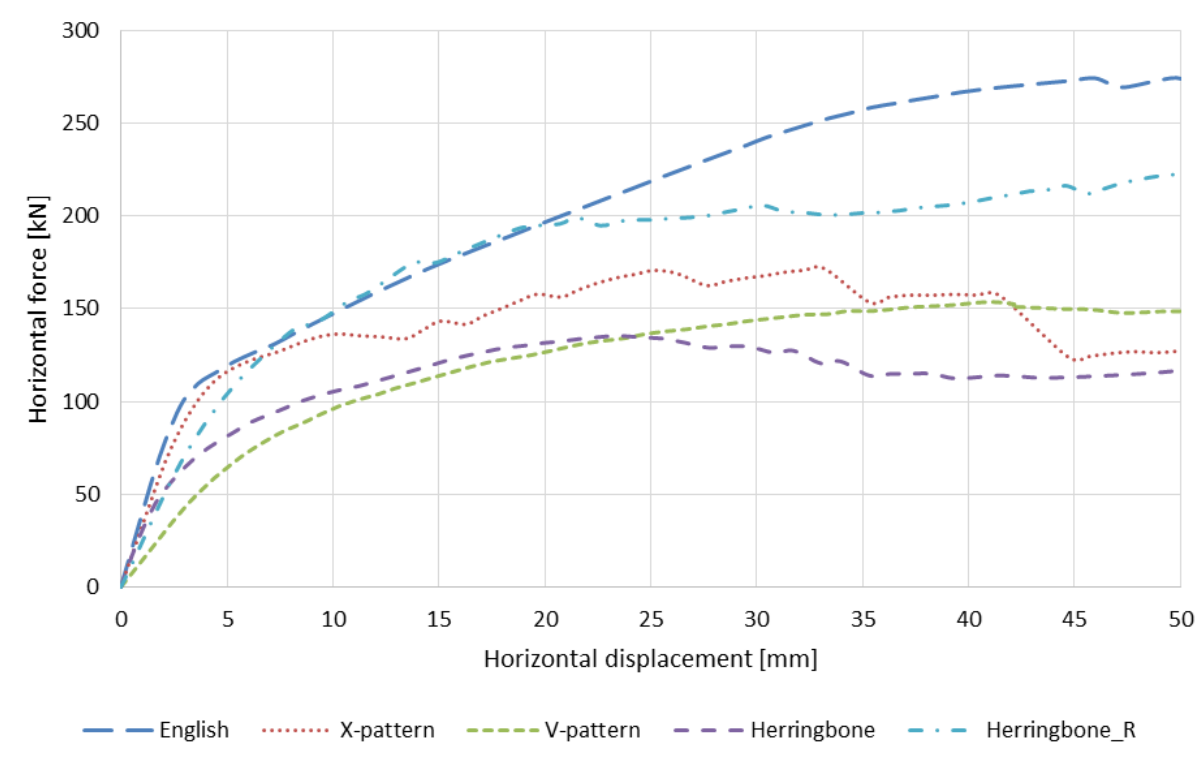

Fig. (3.1). The horizontal force-displacement diagrams for the case of the largest vertical load.

In case of the highest vertical load $(86.96 \mathrm{kN} / \mathrm{m})$, perhaps in contrast with the expectations, the classical English wall had the largest resistance to shear (Fig. 3.1). The next one was the Herringbone_R wall, then the X-pattern and Vpattern walls followed. Note that the resistance of the herringbone wall is highly dependent on the direction of the shear load (more than $30 \%$ in the shear forces).

Considering the crack patterns (captured at $40 \mathrm{~mm}$ horizontal displacement) for the English, X-pattern and Herringbone walls (Fig. 3.2, from left to right), the failure mechanism was always diagonal cracking (as well as in the other two cases, V- and reversed herringbone pattern, not shown here). Since there is no horizontal shear plane in case of the highest vertical load, the vertically installed bricks do not improve the shear performance of the walls (actually their presence seems to slightly reduce it due to the rotation of the vertical bricks along the diagonal cracking), thus the English wall supports the highest horizontal load.
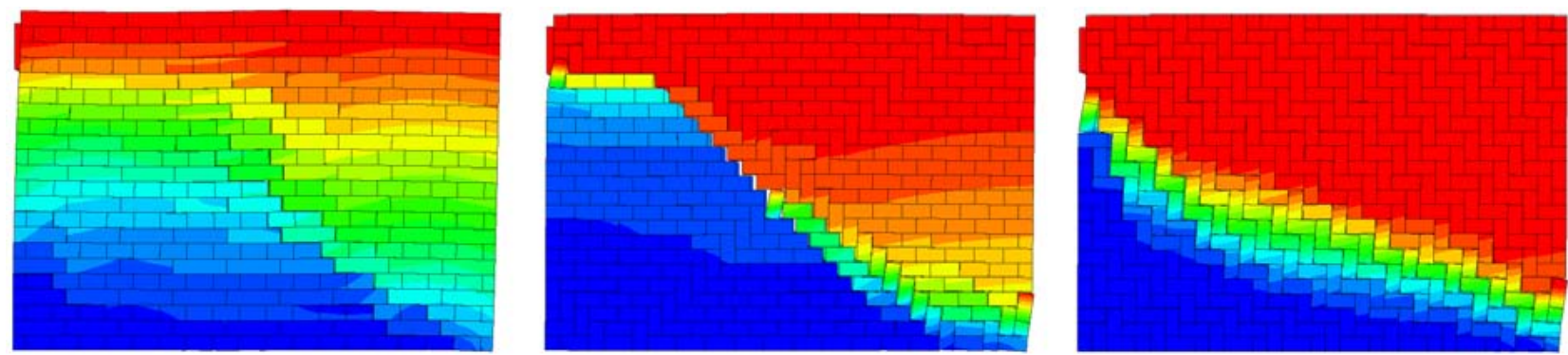

Fig. (3.2). Crack patterns for the case of the largest vertical load $(86.96 \mathrm{kN} / \mathrm{m})$. Color scale indicates displacement magnitude (from left to right: English, X-pattern and Herringbone).

Now consider the case of the lowest vertical load. From the detected force-displacement diagrams (Fig. 3.3), contrary to the previous case considering a large vertical load, the Herringbone_R and X-pattern walls have the largest load bearing capacity, and the English wall practically shows the worst performance. 


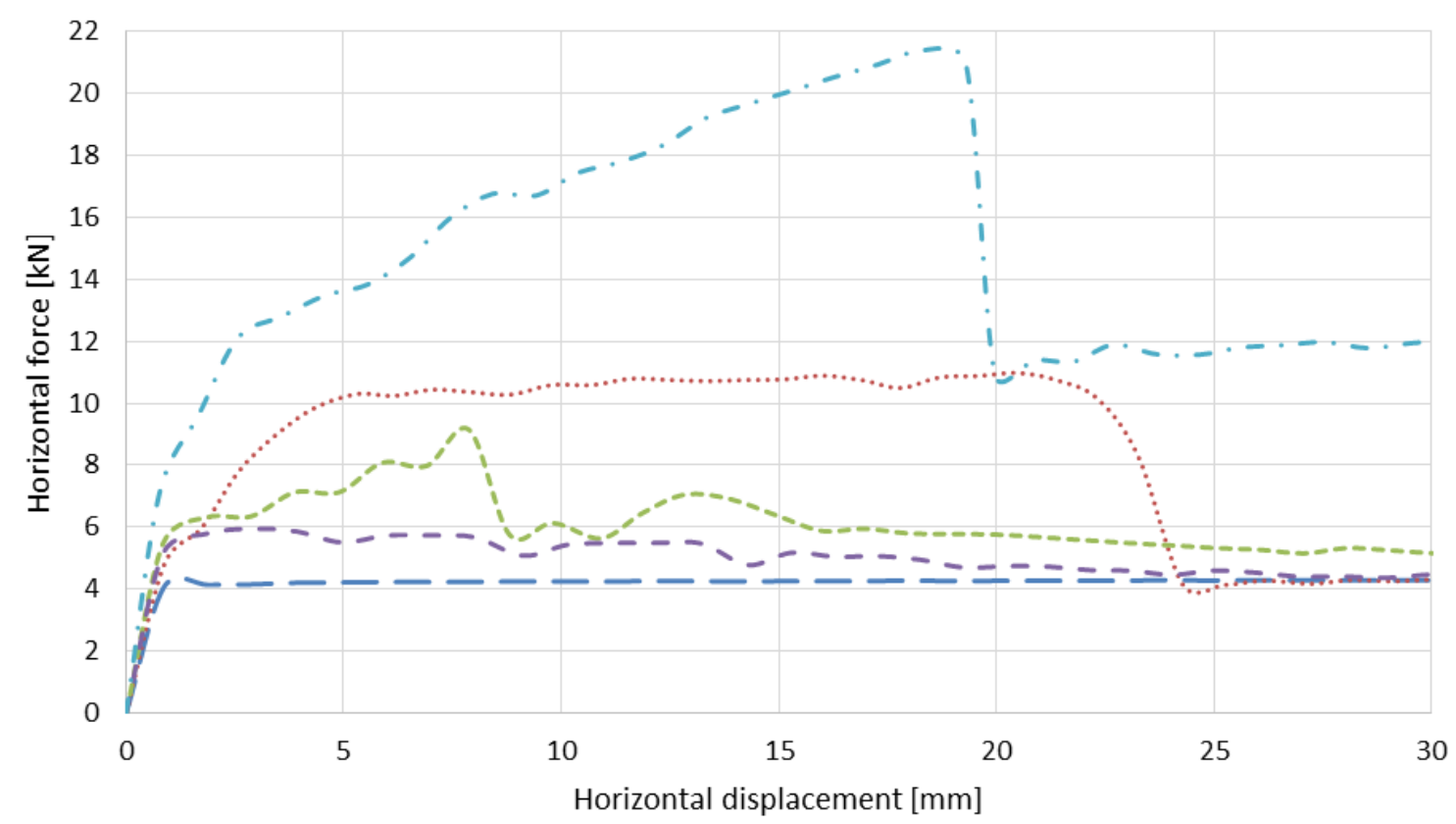

- English $\quad \cdots . . . . . \times$ X-pattern -----V-pattern - - - Herringbone - - Herringbone_R

Fig. (3.3). The horizontal force-displacement diagrams for the case of the lowest vertical load.

To get a better understanding of this, the crack patterns captured at $20 \mathrm{~mm}$ horizontal displacement of the same walls are shown again Fig. (3.4). In case of the English wall a horizontal shear plane develops, but at the other walls the diagonal cracking (which is a combination of horizontal sliding and separation of vertical joints) remains the failure mode, thus now the vertical bricks indeed improve the shear performance of the walls.
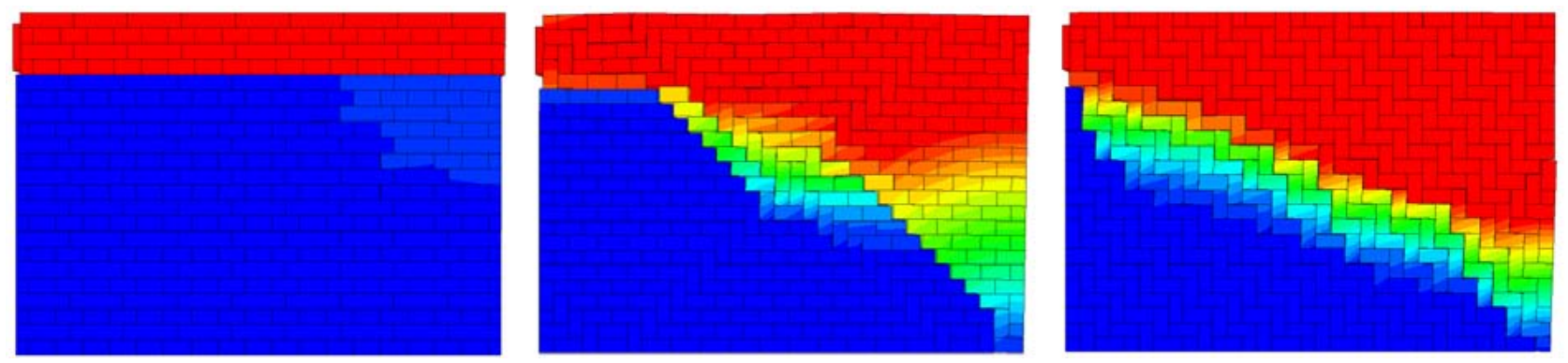

Fig. (3.4). Crack patterns for the case of the lowest vertical load $(0.87 \mathrm{kN} / \mathrm{m})$. Color scale indicates displacement magnitude (from left to right: English, X-pattern and Herringbone).

Compare now the load bearing capacity of the different walls under the six different vertical load magnitudes. Fig. (3.5) shows this load bearing, normalized with the magnitude of the vertical load, as the function of the vertical load itself (along the horizontal axis the magnitude of the vertical load is in logarithmic scale). It can be concluded that the vertically installed bricks only help when the vertical load is low (up to about $4.35 \mathrm{kN} / \mathrm{m}$ ). Above this limit the classical English wall shows the best shear performance. 


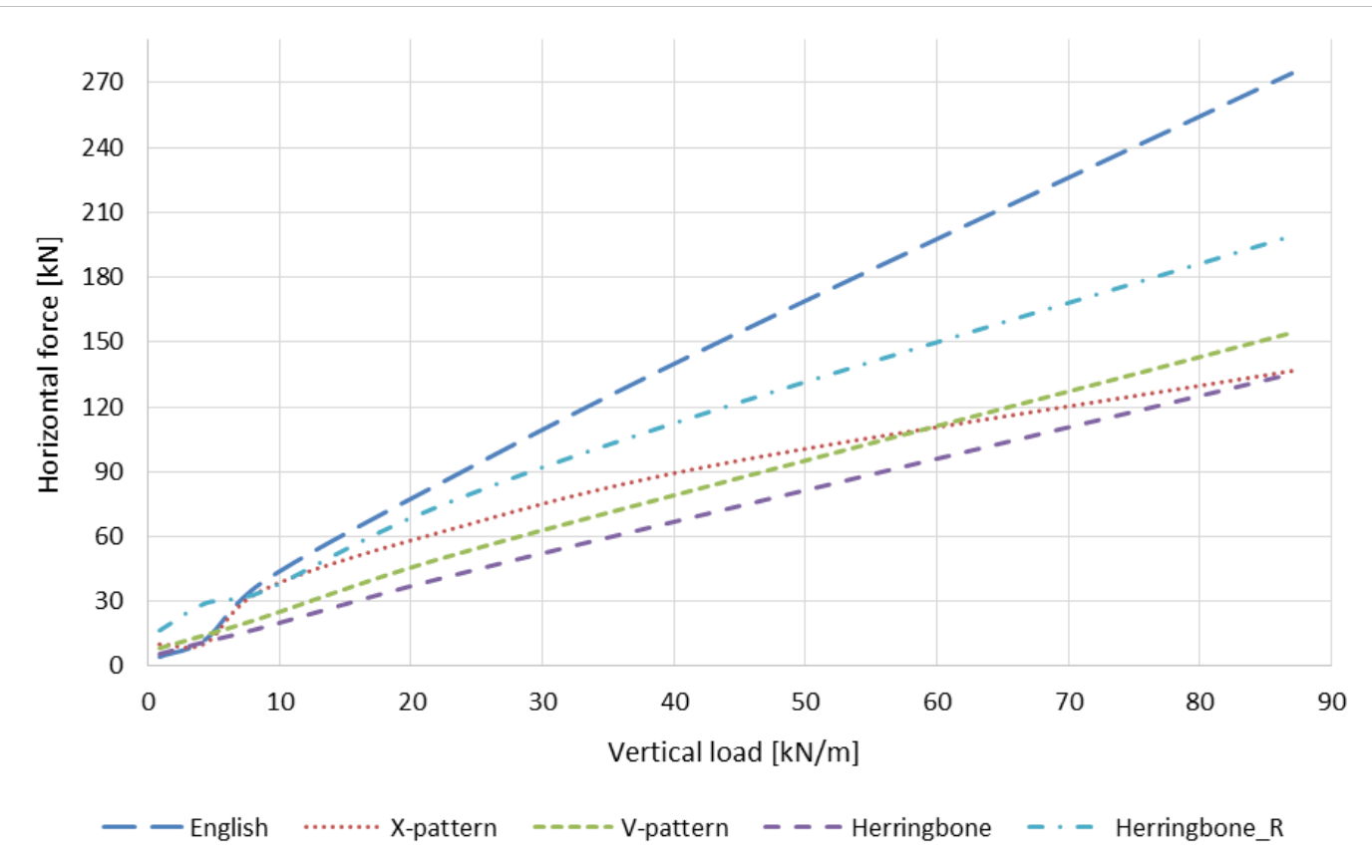

Fig. (3.5). The load bearing capacities of the walls depending on the vertical load magnitude.

\subsection{Shear Behaviour in Terms of the Length-to-Height Ratio}

The second mean factor modifying the shear resistance is the $l / h$ ratio of the walls. For every pattern described previously, we studied four different lengths. All of them considered two vertical load magnitudes: 4.35 and 21.74 $\mathrm{kN} / \mathrm{m}$. Consider first the case of the lowest vertical load magnitude (Fig. 3.6).

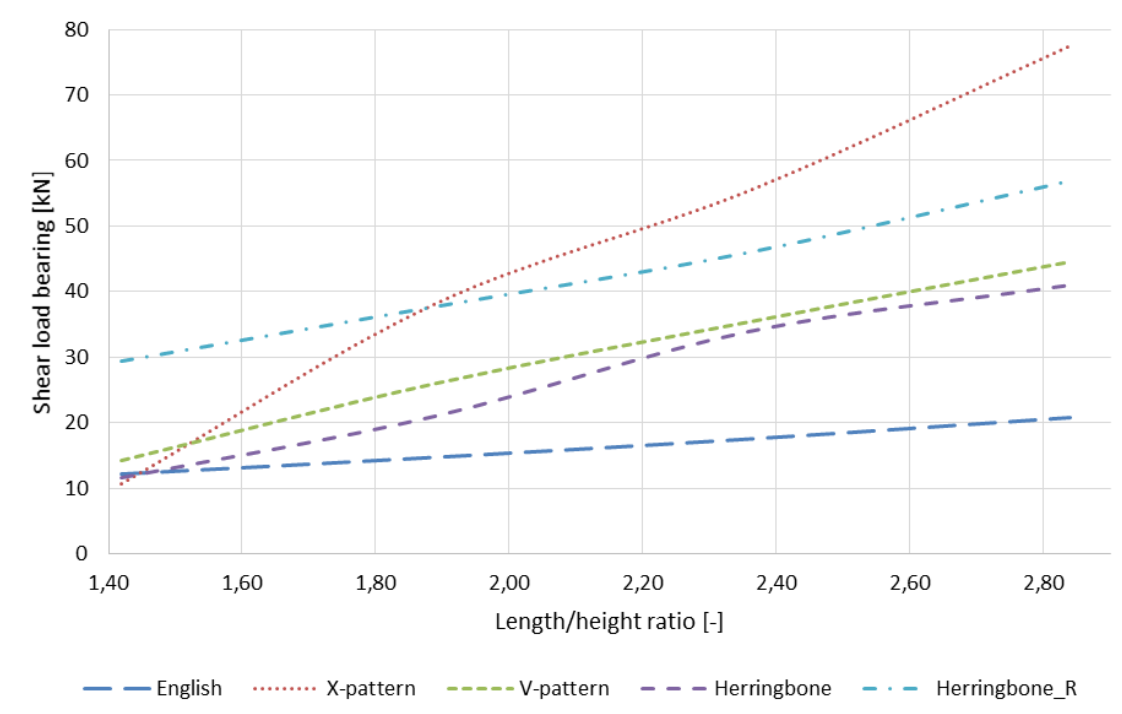

Fig. (3.6). Effect of the $l / h$ ratio for $4.35 \mathrm{kN} / \mathrm{m}$ vertical load.

In all cases, the shear load bearing capacity turned out to be an approximately linear function of the length to height ratio. Since the vertical load resultant increases proportionally with the length of the wall, according to the applied Coulomb frictional law, the resistance should be a monotonically increasing function of the length assuming that failure mode does not change with increasing length. Indeed, it was found for all patterns that the failure mechanism did not depend on the length to height ratio: the mode occurring for the shortest wall of a certain pattern was valid for all lengths belonging to that same pattern. 
English wall has the smallest shear resistance (Fig. 3.7) (captured slightly after the ultimate load) shows that a sliding failure mode occurs for English walls, while a diagonal cracking happens in the case of the other patterns (as a characteristic example, the herringbone pattern is shown). The low load bearing of the English wall in comparison to the other patterns is explained by the position of the sliding surface: for all $l / h$ ratios, the plane is near the top of the wall, at the same height for every length. The compression along this surface is produced by the vertical load on top plus the weight of the bricks above the sliding plane. At patterns where some of the sliding horizontal contacts carry larger compression than others (see the herringbone pattern in (Fig. 3.7) for example), the contribution of the lower contacts to the shear resistance is more significant leading to higher load bearing capacity.
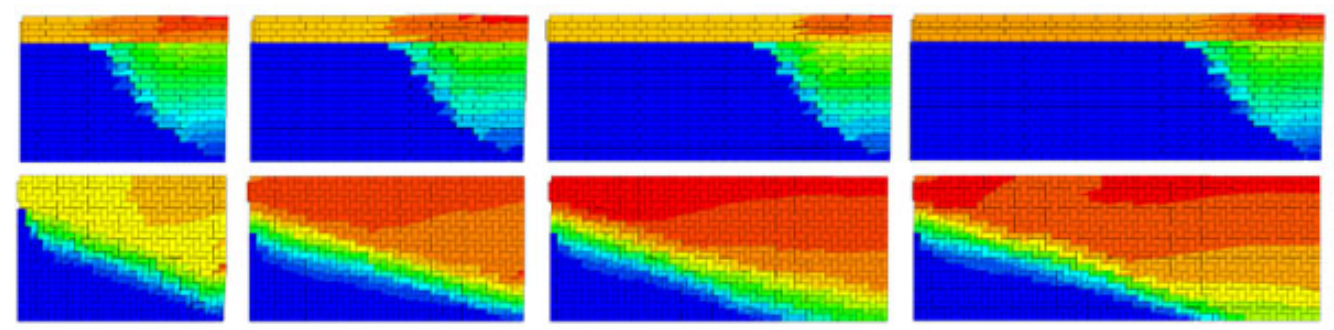

Fig. (3.7). Failure modes for different $l / h$ ratios for $4.35 \mathrm{kN} / \mathrm{m}$ vertical load. Color scale indicates displacement magnitude (up: English bond, down: Herringbone).

At medium vertical load magnitudes Fig. (3.8) the resistance of the walls increases with the length. For long walls the X-pattern and herringbone_R walls have the highest load bearing capacity, while in the shortest case the English shows the best resistance.

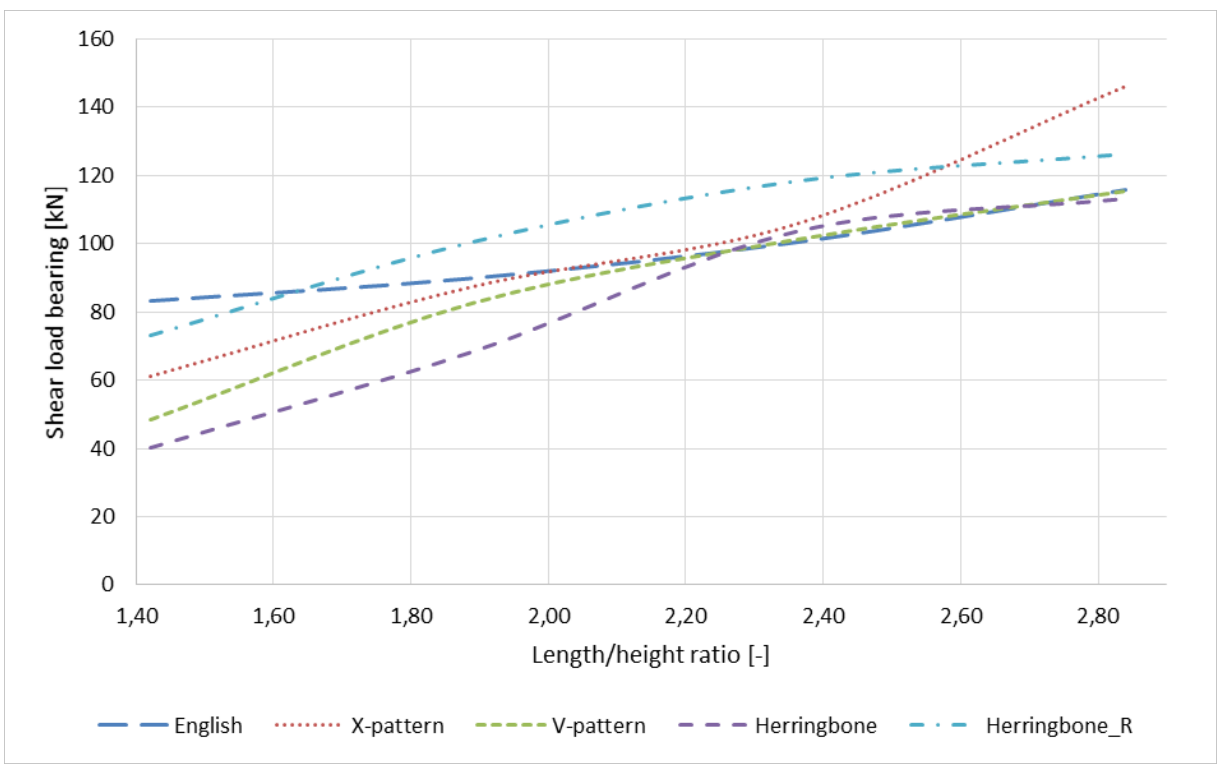

Fig. (3.8). Effect of the $l / h$ ratio for $21.74 \mathrm{kN} / \mathrm{m}$ vertical load.

The damage modes in Fig. (3.9) offer the following explanation: In case of the English pattern, at the shortest wall a combined diagonal cracking and horizontal sliding failure occurs which implies higher shear resistance. However, with increasing length to height ratio the horizontal sliding failure becomes dominant over the combined mode, resulting in the decreasing of the shear performance. At the Herringbone pattern instead of sliding, the rotation of the vertical bricks can be noticed along the diagonal failure surface, thus lower horizontal force is enough to displace the wall (similar mechanism was found at all other patters containing vertical bricks). Indeed, by the comparison of the shortest walls in Fig. (3.9), at both patterns similar diagonal failure surface appears, but the English pattern has the larger resistance. In case of long walls with vertical bricks a significantly larger part of the wall is moving in comparison with the English pattern because of the different failure modes, leading to higher resistance. 

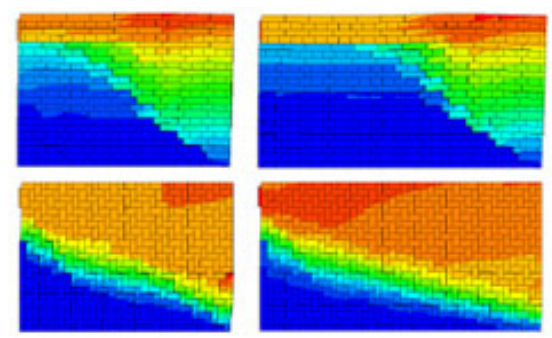
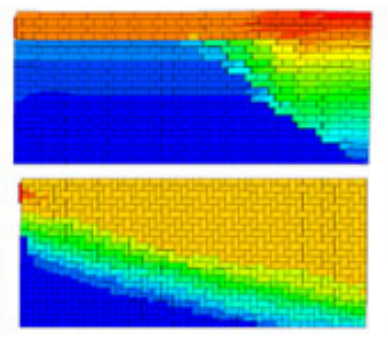

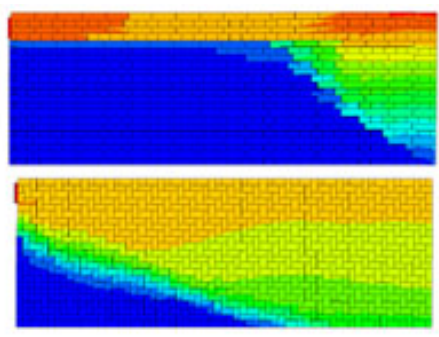

Fig. (3.9). Failure modes for different $l / h$ ratios beside $21.74 \mathrm{kN} / \mathrm{m}$ vertical load. Color scale indicates displacement magnitude (up: English bond, down: Herringbone).

\section{CONCLUSION}

In this study masonry walls with different bond patterns were investigated under monotonically increasing horizontal shear, with a particular attention to the effect of a constant vertical load magnitude and of the length/height ratio of the wall. It turned out that the stabilizing effect of the vertical load plays a very important role in the shear performance:

$\rightarrow$ In case of low magnitudes it was found that walls without vertically installed bricks are susceptible to fail with horizontal shear plane which leads to a lower shear resistance.

$\rightarrow$ In case of high vertical load magnitudes the characteristic failure mode was diagonal cracking or combined diagonal and sliding failure at all bond patterns, and the classical English wall showed the best performance against horizontal shearing.

In contrast with the vertical load magnitude, the $l / h$ ratio did not significantly affect the failure mode of the walls, thus if the failure mode was a horizontal shear plane, the ultimate load was practically a linear function of the length of the wall. At patterns containing vertical bricks, instead of sliding the rotation of the vertical bricks can be noticed along the diagonal failure surface, which also affects the magnitude of the ultimate load.

Walls with herringbone (i.e. non-symmetric) pattern turned out to be rather sensitive to the direction of the shear load: more than $30 \%$ difference was detected according to the direction of the loading. Consequently, this pattern can be beneficial only in those cases where the direction of the shear load is known and remains unchanged. However, it is not valid for usual shear loads in the engineering practice (earthquake, soil motions).

To summarize, the results show that the application of vertical bricks in the bond pattern does not necessarily lead to an increased shear resistance: the magnitude of the vertical load and the length to height ratio determine which bond pattern leads to the highest shear resistance.

\section{CONFLICT OF INTEREST}

The authors confirm that this article content has no conflict of interest.

\section{ACKNOWLEDGEMENTS}

The authors express their gratitude to the Itasca Education Partnership for the generous contribution of 3DEC software to this research. Financial support from the OTKA 100770 project is also gratefully acknowledged.

\section{REFERENCES}

[1] D. O’Dwyer, "Funicular analysis of masonry vaults", Comput. Struc., vol. 73, no. 1-5, pp. 187-197, 1999. [http://dx.doi.org/10.1016/S0045-7949(98)00279-X]

[2] P. Block, and J. Ochsendorf, "Thrust network analysis: A new methodology for three-dimensional equilibrium", J. IASS., vol. 48, no. 3, p. $155,2007$.

[3] C. Baggio, and P. Trovalusci, "Collapse behaviour of three-dimensional brick-block systems using non-linear programming", Struct. Eng. Mech., vol. 10, no. 2, pp. 181-195, 2000.

[http://dx.doi.org/10.12989/sem.2000.10.2.181]

[4] P. Roca, M. Cervera, G. Gariup, and L. Pela, "Structural analysis of masonry historical constructions, classical and advanced approaches", Arch. Comput. Methods Eng., vol. 17, no. 3, pp. 299-325, 2010.

[http://dx.doi.org/10.1007/s11831-010-9046-1] 
[5] D. Baraldi, A. Cecchi, and A. Tralli, "Continuous and discrete models for masonry like material: A critical comparative study for similar discussion and numerous references", Eur. J. Mech. A, Solids, vol. 50, pp. 39-58, 2015. [http://dx.doi.org/10.1016/j.euromechsol.2014.10.007]

[6] V. Giamundo, V. Sarhosis, G.P. Lignola, Y. Sheng, and G. Manfredi, "Evaluation of different computational modelling strategies for modelling low strength masonry", Eng. Struct., vol. 73, pp. 160-169, 2014. [http://dx.doi.org/10.1016/j.engstruct.2014.05.007]

[7] P. Trovalusci, and R. Masiani, "Non-linear micropolar and classical continua for anisotropic discontinuous materials", Int. J. Solids Struct., vol. 40, pp. 1281-1297, 2003.

[http://dx.doi.org/10.1016/S0020-7683(02)00584-X]

[8] S. Casolo, "Macroscopic modelling of structured materials: Relationship between orthotropic Cosserat continuum and rigid elements", Int. J. Solids Struct., vol. 43, pp. 475-496, 2006. [http://dx.doi.org/10.1016/j.ijsolstr.2005.03.037]

[9] P. Trovalusci, and A. Pau, "Derivation of microstructured continua from lattice systems via principle of virtual works: the case of masonrylike materials as micropolar, second gradient and classical continua", Acta Mech., vol. 225, pp. 157-177, 2014. [http://dx.doi.org/10.1007/s00707-013-0936-9]

[10] V. Sarhosis, and Y. Sheng, "Identification of material parameters for low bond strength masonry", Eng. Struct., vol. 60, pp. 100-110, 2014. [http://dx.doi.org/10.1016/j.engstruct.2013.12.013]

[11] A. Fódi, "Experimental and numerical investigation of reinforced and plain masonry walls", Ph.D. Thesis, Budapest University of Technology and Economics, Hungary, 2011.

[12] P.A. Cundall, "A computer model for simulating progressive large-scale movements in block rock mechanics", In: Proceedings of the Symposium of the International Society of Rock Mechanics, Nancy: France, vol. 1, Paper No. II, 1971.

[13] P.A. Cundall, and D.H. Hart, "Numerical modelling of discontinua", J. Eng. Comput, vol. 9, pp. 101-113, 1972. [http://dx.doi.org/10.1108/eb023851]

[14] C. O’Sullivan, Particulate discrete element modelling: A geomechanics perspective. Spon Press, Taylor and Francis, 2011.

[15] J.V. Lemos, "Discrete element modelling of masonry structures", Int. J. Archit. Herit., vol. 1, pp. 190-213, 2007. [http://dx.doi.org/10.1080/15583050601176868]

[16] S. Huerta, "The analysis of masonry architecture: A historical approach", Archit. Sci. Rev., vol. 51, no. 4, pp. 297-328, 2008. [http://dx.doi.org/10.3763/asre.2008.5136]

[17] V. Sarhosis, K.D. Tsavdaridis, and I. Giannopoulos, "Discrete element modelling of masonry infilled steel frames with multiple window openings subjected to lateral load variations", Open Constr. Build. Technol. J., vol. 8, pp. 93-103, 2014. [http://dx.doi.org/10.2174/1874836801408010093]

[18] Porotherm, 2014.[Accessed: 03 January 2015] Kisméretű tömör tégla [online]. Catalogue in Hungarian. Available at: http://www.wienerberger.hu/egy\%C3\%A9b-term\%C3\%A9kek/online-term $\%$ C3\%A $\%$ kkatal $\% \mathrm{C} 3 \% \mathrm{~B} 3 \mathrm{gus} / \mathrm{kism} \% \mathrm{C} 3 \% \mathrm{~A} 9 \mathrm{ret} \% \mathrm{C} 5 \% \mathrm{~B} 1-\mathrm{t} \% \mathrm{C} 3 \%$ $\mathrm{B} 6 \mathrm{~m} \% \mathrm{C} 3 \% \mathrm{~B} 6 \mathrm{r}-\mathrm{t} \% \mathrm{C} 3 \% \mathrm{~A} 9 \mathrm{gla}$

CSzakaly et al.; Licensee Bentham Open.

This is an open access article licensed under the terms of the Creative Commons Attribution-Non-Commercial 4.0 International Public License (CC BY-NC 4.0) (https://creativecommons.org/licenses/by-nc/4.0/legalcode), which permits unrestricted, non-commercial use, distribution and reproduction in any medium, provided the work is properly cited. 